\title{
Functional classification dictates type of repair in "complex" mitral insufficiency: Application to a case of a hammock mitral valve in an adult patient
}

\author{
Rachid Zegdi, MD, PhD, ${ }^{\mathrm{a}, \mathrm{b}}$ Ziad Khabbaz, MD, ${ }^{\mathrm{b}}$ Sylvain Chauvaud, MD, ${ }^{\mathrm{b}}$ Philippe Garçon, MD, ${ }^{\mathrm{a}, \mathrm{b}}$ \\ Alain Carpentier, MD, PhD, and Alain Deloche, MD, ${ }^{\mathrm{a}, \mathrm{b}}$ Paris, France
}

$\mathrm{T}$ he hammock mitral valve is a rare congenital abnormality resulting in mitral stenosis, mitral regurgitation, or both. Although sometimes technically challenging, the repair of such lesion is possible ${ }^{1}$ and should be preferred to mitral valve replacement. ${ }^{2}$ We describe here for the first time the case of an adult patient who underwent mitral valve repair for severe mitral regurgitation related to a hammock mitral valve malformation.

\section{Clinical Summary}

An 18-year-old woman was referred to our department for surgical treatment of severe mitral valve regurgitation. She had symptoms and signs of congestive heart failure. There were no signs or history of endocarditis, and her previous medical history was free from rheumatic heart disease. Transesophageal echocardiography showed 4+/4 mitral regurgitation and dilated left cardiac cavities. There was no mitral stenosis or other cardiac malformation. The careful analysis of the mitral valve anatomy confirmed a hammock mitral valve by showing the presence of a unique overdeveloped papillary muscle, originating high on the posterior wall of the left ventricle, just underneath the mural leaflet (Figure 1). This papillary muscle had the shape of a large muscular band, and the chordae were short, distributing to both leaflets. The mitral annulus was also dilated.

At operation, direct inspection confirmed the presence of a hammock mitral valve and confirmed the feasibility of the mitral valve repair. Mitral insufficiency was related to the restricted motion of both leaflets (type IIIlb of the Carpentier classification). Annular dilation was also present. The muscular band was split into anterior and posterior parts and partially detached from the posterior wall. Secondary chordae to the posterior mitral valve were also cut to improve the leaflet mobility. Annular dilation was corrected with implantation of a Carpentier-Edwards Physio-Ring 30 (Baxter Healthcare Corporation CardioVascular Group, Irvine, Calif). Postoperative transesophageal echocardiography showed a continent mitral valve with a

From Université René Descartes-Paris $\mathrm{V}^{\mathrm{a}}$ and the Department of Cardiovascular Surgery, Georges Pompidou European Hospital, ${ }^{\text {b }}$ Paris, France.

Received for publication Oct 28, 2004; revisions received Nov 4, 2004; accepted for publication Nov 5, 2004.

Address for reprints: Rachid Zegdi, MD, Hôpital Européen Georges Pompidou, Service de Chirurgie Cardiovasculaire, 20, rue Leblanc, 75908 Paris, France (E-mail: rzegdi@ hotmail.com).

J Thorac Cardiovasc Surg 2005;130:217-18

$0022-5223 / \$ 30.00$

Copyright $\odot 2005$ by The American Association for Thoracic Surgery

doi:10.1016/j.jtcvs.2004.11.056 large surface of coaptation between the two leaflets (Figure 1). The patient's hospital course was unremarkable.

\section{Discussion}

The hammock mitral valve is a rare congenital malformation of the mitral valve, with incidences ranging from $0 \%$ to $12 \%$ in pediatric surgical series. ${ }^{2,3}$ It is usually associated with severe mitral stenosis, regurgitation, or both and therefore causes symptoms at a young age. The hammock mitral valve is due mainly to a malformation in the subvalvular apparatus. The papillary muscles are aberrant, usually constituted by a unique overdeveloped posterior papillary muscle, originating high on the posterior wall of the left ventricle, just underneath the mural leaflet. This papillary muscle has the shape of a large muscular band. Chordae are short, distributing to the two leaflets, giving them the shape of a hammock.

The surgical repair of mitral regurgitation caused by a hammock mitral valve has been previously described in the pediatric population by Carpentier and colleagues. ${ }^{1}$ To the best of our knowledge, this surgical repair in an adult patient has not previously been reported. This may reflect the fact that few patients reach adulthood with such an uncorrected malformation, or it may reflect the tendency of most surgeons to replace such severely altered valves in adult patients, rather than hazarding a complex repair procedure.

The feasibility of mitral valve repair for mitral regurgitation relies on two "golden rules" proposed by Carpentier. ${ }^{4}$ First is the presence of a sufficient amount of valvular tissue (relative to the annulus size); second is the "flexibility" of this tissue (fibrotic or calcified valves are not adequate for repair). This feasibility is judged during the preoperative echocardiographic studies and finally confirmed during valve inspection at operation.

When facing such an unusual case, the surgeon should keep in mind that understanding the exact mechanism of mitral valve regurgitation is the cornerstone for any successful mitral valve repair. ${ }^{4}$ In this case, the main factor responsible for the mitral regurgitation was the limited movement of the posterior leaflet, resulting from excess traction from malformed chordae and malpositioned papillary muscle. Improvement of leaflet mobility was obtained first by partially detaching the abnormal muscle band from its insertion to the posterior left ventricular wall (Figure 2) and second by incising it sagittally into halves, in an attempt to create two separate "papillary muscles." Finally, further mobility was obtained by the section of the secondary chordae of the mural leaflet. Because enough valve tissue was present, a pericardial patch extension of the posterior leaflet was not done. ${ }^{5}$

The regurgitation was further aggravated by annular distention, which was corrected by insertion of a prosthetic ring. Sizing of the ring is particularly important in type IIIb mitral regurgitation 

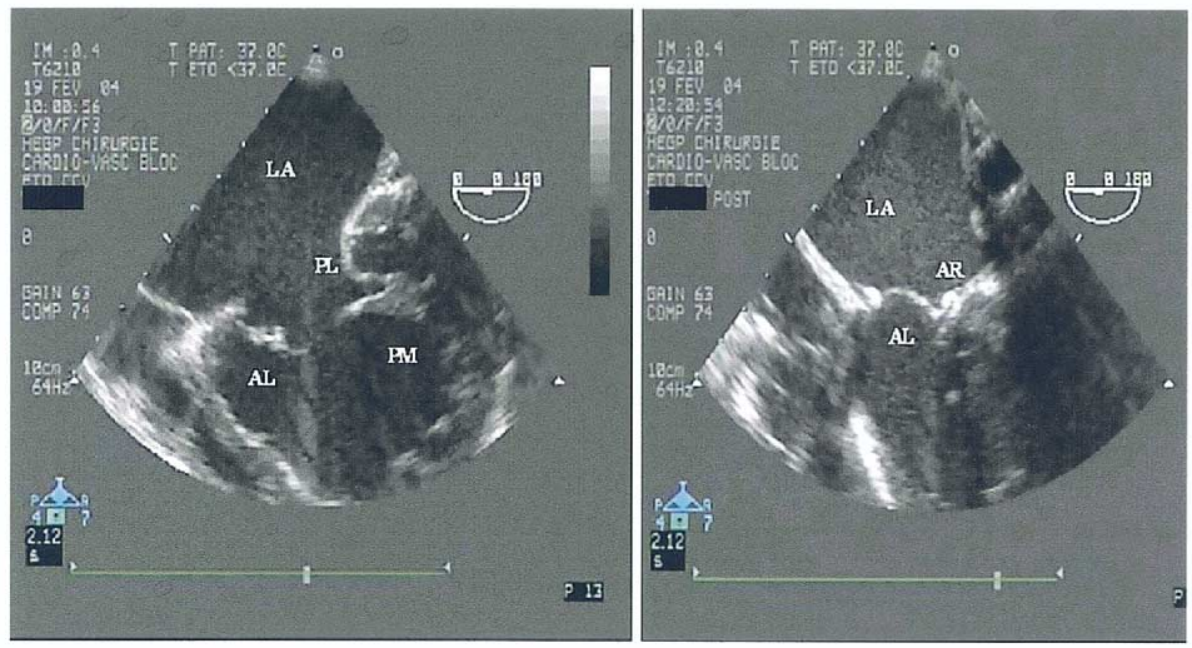

Figure 1. Left, Unique overdeveloped and upward displaced papillary muscle is clearly shown on preoperative transesophageal echocardiographic study. Right, Transesophageal echocardiographic control of mitral valve repair. Good leaflet coaptation was achieved with no residual leak. $L A$, Left atrium; $P L$, posterior leaflet; $A R$, annuloplasty ring; $A L$, anterior leaflet; $P M$, papillary muscle.
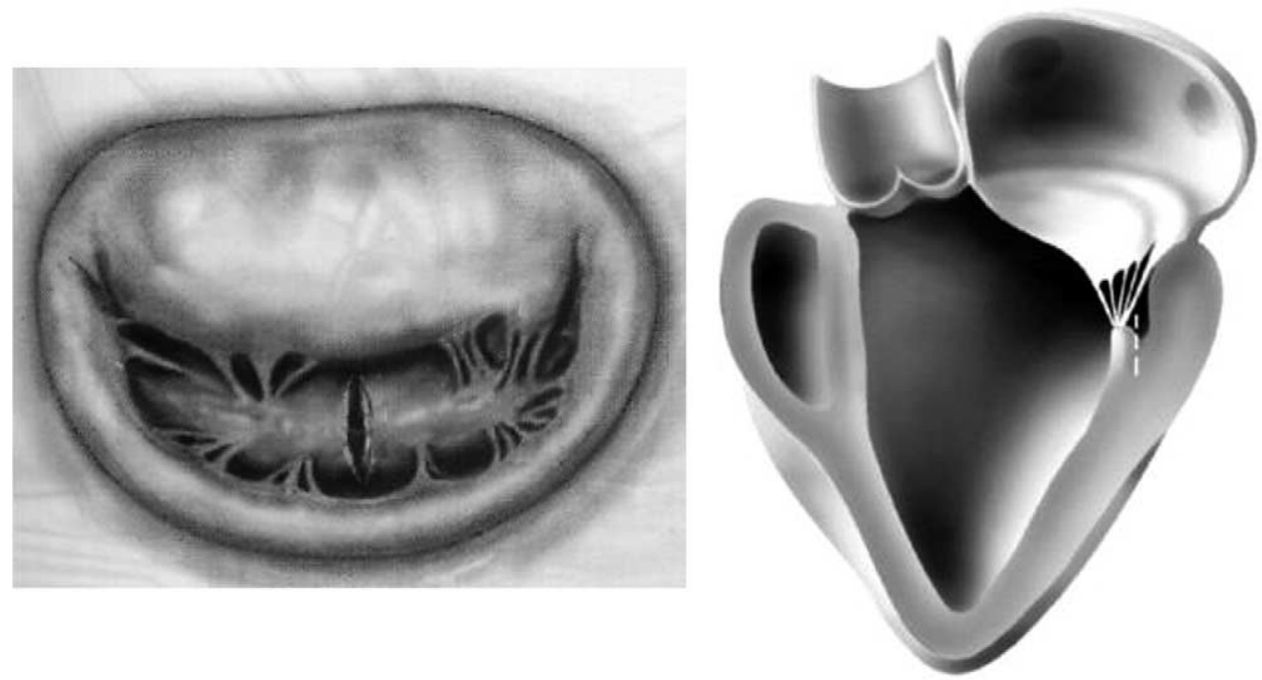

Figure 2. Schematic representation of papillary muscle detachment (interrupted line) in mitral valve repair of hammock mitral valve.

(Carpentier classification). In accordance with the height of the anterior leaflet and the intercommissural distance, an undersized ring was chosen to obtain satisfactory leaflet coaptation. ${ }^{4}$ These two surgical steps led to a successful result, with no residual leakage and no gradient across the mitral valve.

\section{References}

1. Carpentier A, Branchini B, Cour JC, Asfaou E, Villani M, Deloche A, et al. Congenital malformations of the mitral valve in children. Pathology and surgical treatment. J Thorac Cardiovasc Surg. 1976;72:854-66.
2. Chauvaud S, Fuzellier JF, Houel R, Berrebi A, Mihaileanu S, Carpentier A. Reconstructive surgery in congenital mitral valve insufficiency (Carpentier's techniques): long-term results. J Thorac Cardiovasc Surg. 1998;115:84-93.

3. Yoshimura N, Yamaguchi M, Oshima Y, Oka S, Ootaki Y, Murakami $\mathrm{H}$, et al. Surgery for mitral valve disease in the pediatric age group. J Thorac Cardiovasc Surg. 1999;118:99-106.

4. Carpentier A. Cardiac valve surgery: the "French correction." J Thorac Cardiovasc Surg. 1983;86:323-37.

5. Chauvaud S, Jebara V, Chachques JC, El Asmer B, Mihaileanu S, Perrier $\mathrm{P}$, et al. Valve extension with glutaraldehyde-preserved autologous pericardium: results in mitral valve repair. $J$ Thorac Cardiovasc Surg. 1991;102:171-8. 